\title{
Necessidade e contingência do efeito da causa primeira: uma comparação entre Tomás de Aquino e Avicena
}

Julio A. Castello Dubra

castellodubra@gmail.com

Universidad de Buenos Aires - CONICET, Buenos Aires, Argentina

resumo 0 presente artigo trata do caráter contingente ou necessário da relação causal entre a causa primeira e seu efeito, tal como apresentada por Avicena e Tomás de Aquino. Para tanto, aborda o paralelismo no tratamento da inteligência e vontade divinas por parte de ambos os autores. Ambos aceitam que Deus conhece a si mesmo e, conhecendo-se, conhece aquilo que the é distinto. Aceitam igualmente que Deus quer ou ama a si mesmo e, querendo a si mesmo, quer acidentalmente o que lhe é distinto. No entanto, discordam com respeito à necessidade ou contingência do mundo. Para Avicena, o mundo é possível em si mesmo, mas "necessário por outro". Para Tomás, que Deus queira o mundo com necessidade hipotética corresponde mais à necessidade do querer divino, sem que isso determine a contingência ou necessidade do mundo. Com efeito, na visão tomista, é preferível um universo no qual haja mescla de necessidade e contingência, pois isso representa melhor as múltiplas perfeições divinas.

palavras-chave Necessidade; contingência; Avicena; Tomás de Aquino

Desde seus primórdios, a metafísica ocidental evidencia um caráter manifestamente protológico e o discurso sobre o ser constitui-se como um discurso sobre o princípio. A ambiguidade de um testemunho sobre Anaximandro não nos permite saber se ele foi o primeiro a dar um nome ao princípio, o de ápeiron, ou se foi o primeiro a utilizar o nome mesmo de princípio, arkhé, naquele sentido que fará uma longa carreira na

Recebido em 17 de novembro de 2009. Aceito em 29 de janeiro de 2010.

Tradução: Marina dos Santos - UFRGS

doispontos, Curitiba, São Carlos, vol. 7, n. 1, p.69-94, abril, 2010 
história da filosofia. Daí por diante, todo o pensamento pré-socrático foi classificado segundo os diferentes tipos de resposta à pergunta pelos princípios e pelas causas ${ }^{1}$ de todo o real, pelo menos segundo os esquemas da doxografia aristotélica. Em todo caso, com Platão e Aristóteles, consagra-se a idéia da filosofia como uma busca pelo princípio. Aristóteles caracteriza o saber mais elevado, a sophía, como um conhecimento de certas causas ou princípios, a saber, os primeiros. $\mathrm{O}$ aprofundamento dessa caracterização leva, pouco a pouco, a palavra 'princípio' a ser declinada no singular e a ser destacada em maiúscula: o Princípio, o primeiro de toda a realidade. Essa tendência consubstancia-se no neoplatonismo tardio, onde o objeto da especulação filosófica é mostrar a seqüência, ao mesmo tempo, lógica e real, segundo a qual tudo brota de um mesmo princípio e retorna a ele.

A postulação do princípio responde a uma exigência racional de explicação última. Enquanto tal, essa exigência contém duas orientações divergentes. De um lado, pareceria tender a vincular necessariamente o princípio com aquilo que é explicado por ele. Se o princípio é verdadeiramente princípio, com verdadeiro e absoluto poder explicativo, deve ficar claro como tudo se segue necessariamente a partir dele. De outro lado, pareceria que o princípio, se é verdadeiramente princípio precisa ser devidamente distinguido de tudo aquilo que se segue dele, de tudo aquilo que não é o princípio, parecerá necessário que o princípio esteja desvinculado ou desligado de qualquer outra coisa, isto é, que seja considerado terminantemente como o ab-soluto. A suficiência do princípio adquire, assim, duas faces opostas: a suficiência explicativa do princípio tende a ligá-lo necessariamente ao que se segue dele, a "atá-lo" firmemente ao que se une a ele; a suficiência de sua própria condição como o primeiro, o mais perfeito, tende a desvinculá-lo, a fazê-lo livre de todo condicionamento e de todo limite.

A história da tensão entres esses dois lados da suficiência do princípio é também, em grande medida, uma história da bi-implicação entre o ser e o inteligível. Segundo a alegoria do sol da República de Platão, o primeiro princípio é um princípio de todos os princípios, o princípio de todo o domínio daquelas realidades inteligíveis que são, por sua vez, princípios do mundo do vir-a-ser, as Idéias. A Idéia do Bem é não somente causa da ciência e da verdade, isto é, causa da inteligibilidade do 
inteligível, mas também, o fundamento mesmo do ser daquilo que é, causa da ousía, mas sem ser ela mesma ousía e, sim, estando "mais além do ser" (epekeinà tês ousías - PLATÃO, Rep. VI 508e1-b10). Essa frase emblemática inaugura uma consideração do princípio como de uma condição radicalmente distinta de tudo aquilo que deriva dele. Supõe-se que Aristóteles, com sua crítica à "separação" platônica, fez desmoronar todo este mundo inteligível e incorporando-o na physis. Mas, a rigor, a explicação última do movimento e da mudança culmina em uma "forma separada", uma ousía eterna e em ato que acaba não sendo só inteligível, mas também, inteligente, ou melhor, uma intelecção na qual ato e objeto se identificam, uma intelecção da intelecção (nóesis noéseos) (ARISTÓTELES, Met. XII 9, 1074b33-35). Esse ser auto-suficiente e perfeito não pode se rebaixar pensando algo diferente de si mesmo e, por isso, não pode ter outra atividade senão aquela de pensar a si mesmo. Está, pois, desconectado do universo, ao qual move sem, no entanto, atuar diretamente sobre ele ou intervindo nele, mas apenas movendo-o como o desejável e o inteligível movem, "como move o amado" (ARISTÓTELES, Met. XII 7, 1072b3). Plotino representará um retorno a Platão na medida em que volta a um princípio instituído mais além do domínio do ser, o Uno, absolutamente inefável e superior à inteligência, a qual já não pode ser tomada como princípio porque é considerada portadora de uma inevitável dualidade. Mas, em nenhum outro autor, percebe-se melhor a tensão na compreensão da suficiência do princípio. $\mathrm{O}$ ato de engendar está presente na natureza mesmo do Uno - porque o perfeito produz de modo que, quando o Uno está dado, necessariamente deve haver alguma realidade derivada, que é o mesmo que dizer que o Uno necessariamente deve produzir. No entanto, não há sentido em dizer que o Uno "está obrigado" a criar porque não há nada externo a ele que o possa limitar ou constranger e, assim, ele aparece finalmente como aquilo que é totalmente livre.

Quando o desenvolvimento e as derivações dessas especulações são transpostos ao terreno dos autores medievais, é preciso entender que as reformulações se produzem em razão de novas exigências teológicas, fundamentalmente relacionadas à noção de um Deus pessoal, com as características centrais da onipotência, da onisciência e da liberdade. É certo que essas reelaborações continuam exercendo as mesmas forças e a 
mesma história da tensão em torno do modo de conceber a suficiência do princípio. E, aqui também, as distintas propostas de solução constituem, na verdade, novas variações sobre o tema das relações o ser e o inteligível.

No que segue, proponho analisar o problema da necessidade ou contingência do vínculo causal entre a causa primeira e seu efeito tal como pode ser reconstruída nos autores considerados "medievais": Avicena e Tomás de Aquino. Minha intenção é traçar um paralelismo na exposição de ambos os autores, particularmente no tratamento da inteligência e vontade divinas. Para minhas análises, seguirei as linhas gerais da recente obra de Rahim ACAR (2005), embora, na conclusão, eu pretenda destacar uma diferença fundamental que separa Tomás de Aquino de um enfoque como o de Avicena. De um ponto de vista metodológico, convém esclarecer que trabalharei sobre o Avicena latino, principalmente sobre a Metafísica do Livro da cura, o que limita consideravelmente minhas conclusões ao Avicena que foi lido no mundo universitário latino do ocidente. Em segundo lugar, no que diz respeito a Tomás de Aquino, basear-me-ei, sobretudo, no desenvolvimento que ele faz na Suma contra gentiles, o que se pode justificar por diversas razões. Trata-se de uma obra que contém um vasto desenvolvimento dessa questão, o que facilita o acompanhamento dos nexos argumentativos e temáticos, e que apresenta o claro objetivo polêmico de confrontar algumas versões da síntese filosófica greco-árabe e sua recepção no mundo latino-cristão.

\section{II}

Avicena é um dos maiores expoentes da falsafa, da assimilação e apropriação da filosofia grega feitas a partir e para o mundo muçulmano. $\mathrm{Na}$ monumental enciclopédia filosófica e científica que é o Livro da cura, há uma parte culminante que compreende a metafísica ou a ciência divina. Trata-se da primeira apresentação sistemática da metafísica como ciência. Com efeito, aquela ciência sui generis sobre a qual Aristóteles hesitou tanto em sua denominação - sabedoria, filosofia primeira, teologia quanto em seu objeto - o ente enquanto ente ou a substância separada e imóvel, Deus - e que contava com procedimentos argumentativos mais 
próximos à dialética do que às ciências demonstrativas, foi moldada por Avicena como uma ciência com um objeto determinado - o ente enquanto ente - que conta com noções primárias e indefiníveis que são tomadas como ponto de partida: o ente (ens), a coisa (res) e o necessário (AVICENNA 1997 I v, 312-325).

Avicena constrói toda a sua metafísica a partir de uma série de premissas modais que tem por base a distinção, retomada de Al-Farabi, entre o ser possível e o ser necessário. O ser possível caracteriza-se como aquele ser cuja não existência pode ser pensada sem contradição, por oposição ao ser necessário, cuja existência não pode ser negada sem que se entre em contradição (AVICENNA 1926, 66-7). Trata-se de uma distinção chave que visa expressar a rigorosa divisão entre a contingência intrínseca do ser criado e a necessidade absoluta do ser não criado. No entanto, Avicena reformula essa distinção agregando um matiz intermediário. Entre o ser que considerado em si mesmo é possível e o ser que considerado em si mesmo é necessário, Avicena introduz um ser possível em si mesmo, mas necessário por outro.

A partir dessas noções, Avicena elabora o que poderíamos chamar três teses ou teoremas fundamentais de sua metafisica: 1) o ser necessário por si não tem causa; 2) o possível por si tem causa; 3) o possível por si vem a ser necessário por meio de outro. Que o ser necessário não tenha causa, é evidente, pois, caso tivesse causa, sua existência dever-se-ia a esta causa e, nessa medida, considerado em si mesmo, já não seria necessário; e tudo aquilo que, considerado em si mesmo, não é necessário, não é necessário por si. Mas tampouco é possível que aquilo mesmo que é necessário por si seja, por sua vez, necessário por outro, pois, se o necessário por si fosse por outro, sua existência não poderia dar-se sem ele. Mas aquilo que não pode existir sem outro não é necessário por si (AVICENNA, 1977, 4424-37).

Que o possível por si tenha causa, demonstra-se da seguinte maneira. De acordo com sua doutrina da indiferença da natureza ou essência, para Avicena, o possível por si está em si mesmo indeterminado tanto em relação à existência quanto a não existência. Por isso, cabe dizer que, quando existe, adquiriu ou apropriou-se de uma existência distinta da não existência e, quando não existe, adquiriu ou apropriou-se de uma não existência distinta da existência. Em qualquer dos dois casos - tenha ele apropriado-se da existência ou da não existência - isso deve ter ocor- 


\section{4}

rido: [1] em virtude de algo distinto de si ou [2] não. Se [1] é o caso, então, aquilo que é distinto é sua causa (o que se queria demonstrar). Se [2] é o caso, é evidente que tudo aquilo que adquiriu um ser depois do não ser, assim o fez porque algo lhe adveio a partir de outro distinto de si. Assim sendo, ou bem [2.1] a essência mesma da coisa é suficiente para dar conta dessa aquisição ou bem [2.2] não o é. Se foi suficiente, seria já um ser necessário, mas havia sido assumido - ex hypotesi - que se tratava de um ser possível. Mas se a essência da coisa não foi suficiente para dar conta dessa aquisição, a não ser que tenha existência em virtude de algo superveniente, então, sua existência deve-se à existência de outra coisa, da qual precisa para existir, o que equivale a dizer que tem causa. Portanto, em qualquer caso, terá os dois extremos da existência e da não existência não por si mesmo, mas por outra causa. A noção de existência aplicar-selhe-á em razão de uma causa que é causa da existência e a noção de não existência aplicar-se-lhe-á em razão de uma causa que é antes a privação ou a ausência da causa da existência (AVICENNA 1977, 4438-4558).

Por último, demonstra-se que esse possível em si mesmo, do qual se disse que tem necessariamente uma causa, torna-se necessário, precisamente em virtude da sua causa e em relação a ela. Pois, se não fosse necessário pela existência da causa e em comparação a ela, seria sempre possível. Nesse caso, permaneceria ainda indeterminado tanto em relação à existência quanto a não existência e poder-se-ia conceder tanto uma quanto outra, de modo que seria preciso uma terceira coisa, além daquela causa, pela qual seja assinalada uma existência depois da não existência ou uma não existência depois da existência e esta coisa será, por sua vez, outra causa e assim ao infinito. Ora, isso é impossível não porque não seja possível uma série infinita de causas ${ }^{2}$, mas antes porque o possível continuará sem sair de sua indeterminação ao vincular-se a essa série de causas e não terá apropriado-se da existência quando, no começo, havia sido considerado como existente. A conclusão do argumento é, pois, que tudo o que é possível não vem a existir a não ser quando é necessário em relação a sua causa (AVICENNA 1977, 4459-4671).

Se voltarmos ao conteúdo dos três argumentos, teremos que o primeiro demonstra que o ser necessário não tem causa, sob um ponto de vista conceitual, quase como deduzindo analiticamente, da noção mesma do ser necessário por si, o que não tem causa. O segundo argumento 
mostra que o possível em si mesmo, considerado em sua indeterminação, é incapaz de dar conta tanto da sua existência quanto da sua não existência. Mas, como obviamente ele se encontra em algum dos dois casos, deve haver uma causa precisa que o determine até a existência ou até a não existência. O terceiro argumento, por sua vez, parte do possível como realizado, isto é, como existente e demonstra que, se a relação com a causa não o torna necessário, ele permanecerá entregue a sua própria indeterminação e, na eventualidade de que as causas se multipliquem ao infinito, ele não chegará nunca à existência.

Essas três teses, em seu conjunto, estão de acordo com uma interpretação da contingência e da necessidade do universo com a seguinte peculiaridade. De um lado, Avicena afirma uma visão da realidade que contrapõe a condição ontológica do ser possível por si àquela do único ser necessário. Posteriormente, ele demonstrará que o ser necessário assim o é sob qualquer ponto de vista, pois não pode haver dois seres que sejam necessários por si com igual necessidade e que o ser necessário por si não pode ser senão único. Portanto, a distinção entre o possível por si e o necessário por si equivale à distinção absoluta entre a contingência ontológica da criatura e a suficiência ontológica do criador único, do qual aquela depende radicalmente. De outro lado, em razão da argumentação que resumimos, a distinção de base culmina, paradoxalmente, em uma visão fortemente necessitarista do universo, segundo a qual, aquilo que em si mesmo era possível, adquire uma existência necessária a partir de sua causa. No universo aviceniano, tudo o que existe, enquanto existe, é necessário. Tudo o que ganha existência tem necessariamente uma causa e toda causa suficiente - quando nada a impede - implica necessariamente a existência de seu efeito.

Essa visão necessitarista influenciou fortemente o mundo cristão ocidental, no âmbito universitário que tomou contato com Avicena no contexto do processo de recuperação do "novo Aristóteles" nos séculos XII e XIII. O necessitarismo aviceniano, como interpretação dominante da explicação aristotélica do universo, chegou a confundir-se em um único sistema para converter-se quase no modelo da racionalidade explicativa, na visão filosófica do universo. Não por acaso, grande parte das teses condenadas em 1277 relacionam-se com as consequências indesejáveis dessa visão. 
Ao elaborar sua "ciência divina", Avicena procede com uma sequência temática análoga a que Tomás de Aquino seguirá no tratado da essência divina nas Sumas. Depois de tratar da simplicidade divina - excluindo, de Deus, a composição de essência e existência e negando que ele esteja num gênero ou se lhe aplique alguma diferença específica-Avicena passa a considerar a perfeição e a bondade divinas e, na continuação, sua inteligência. A demonstração que o ser necessário é inteligente baseia-se na equação entre inteligibilidade e imaterialidade. O que constitui um obstáculo para a intelecção não é o ser da coisa, mas a matéria e seus acréscimos (appendicia). Pelo contrário, o ser formal, que é inteligível por natureza, é aquilo pelo qual se dá o conhecimento intelectual da coisa. Aquilo que é capaz de receber esse ser inteligível é a inteligência em potência, a qual, quando é aperfeiçoada, vem a ser inteligência em ato. Mas aquilo cuja essência é inteligência, é inteligência por si. Portanto, se a materialidade e seus acréscimos são o obstáculo que impede tanto que a coisa seja inteligida quanto que algo seja inteligente, aquilo que esteja totalmente livre de materialidade e que possua existência separada da matéria, será um inteligível por si e será inteligência por si e, nessa medida, será inteligível para si, ou seja, ele mesmo será o objeto inteligível inteligido por sua própria essência inteligente. Desse modo, em Deus, o objeto da intelecção, o agente que intelige e o ato mesmo da intelecção acabam por coincidir numa unidade apenas discernível conceitualmente, segundo nosso modo de consideração (AVICENNA 1997, 41495_41525).

Numa evidente réplica a Plotino, Avicena esforça-se em explicar que a atribuição de Inteligência ao Primeiro não implica estabelecer uma dualidade n'Ele. Certamente, a inteligência que conhece implica algo conhecido, mas não implica necessariamente que aquilo que é conhecido seja algo distinto - a diferença do que ocorre com o par motor-movido, donde é possível um motor que mova a si mesmo. Portanto, Deus não pode ter um conhecimento através de coisas externas a Ele, pois, nesse caso, sua essência estaria constituída dessa coisa externa que intelige ou bem não teria outra disposição do que a proveniente de causas extrínsecas e, assim, haveria um tipo de “impressão" n’Ele. Mas o fato de Deus possuir um autoconhecimento imediato e intuitivo de sua própria essência não significa que careça do conhecimento de tudo o que não é Ele. 
Pelo contrário, o Deus de Avicena não só deixa de ser o Uno de Plotino que não pode ser inteligência, mas também deixa de ser o Intelecto-Deus de Aristotéles que só intelige a si mesmo e não pode rebaixar-se conhecendo algo inferior a Ele.

Como Deus é o princípio de todo ser, a partir de sua própria essência, ele intelige aquilo de que é princípio, sendo que Ele é princípio dos seres incorruptíveis em sua singularidade e dos geráveis e corruptíveis, primeiramente, em relação a suas espécies e mediante elas, em relação aos indivíduos (AVICENNA 1997, 41495-415²5). Desse modo, chegamos a uma das doutrinas mais características e controvertidas de Avicena: Deus possui um conhecimento dos singulares mutáveis e contingentes "de um modo universal", isto é, das espécies às quais pertencem. Trata-se de uma doutrina cuja difusão gerou uma forte polêmica no século XIII e que motivou a discussão entre os intérpretes atuais (MARMURA 1962). Claramente, Avicena não pretendia defender que Deus não conseguia conhecer os singulares, pois, nesse caso, não poderia ter citado, em pleno contexto filosófico de sua Metafísica, a frase do Corão: "A ti, Senhor, não Lhe passa desapercebido o peso de um átomo na terra nem no céu" (AVICENNA 1997, 41892-4191). De qualquer modo, Avicena deve ter querido dizer que Deus possui um conhecimento dos singulares, mas através de suas espécies. Avicena acredita que não pode ser de outra maneira porque, se Deus possuísse um conhecimento dos singulares em sua individualidade, enquanto sujeitos à variação e à temporalidade, haveria movimento ou mudança em Deus ou bem equivaleria a atribuir-lhe um conhecimento de tipo sensorial. Nesse sentido, o conhecimento que Deus possui dos singulares sensíveis é comparável ao conhecimento científico que o astrônomo possui de um eclipse, que é quem pode determinar suas condições segundo um conhecimento expresso universalmente e baseado em causas sem necessidade de ter uma experiência direta dele (AVICENNA 1997, 42017-42138).

A existência do mundo é, pois, um resultado necessário do conhecimento que Deus possui de seu efeito. Deus conhece a si mesmo e, nessa medida, conhece o que se segue necessariamente d'Ele. Isso poderia ser interpretado no sentido que a criação, enquanto efeito necessário de Deus, é um processo que se dá "espontaneamente" sem que a vontade de Deus intervenha. Nesse sentido, chegou aos autores latinos a versão que, 


\section{8}

para Avicena, Deus atua como um agente natural determinado ad unum, que não pode agir de outra maneira. Mas, a rigor, Avicena opõe-se expressamente a essa concepção ao insistir que a criação não provém de Deus como de um agente que carece de conhecimento e, em tal medida, de vontade.

Para explicar esse ponto, Avicena detém-se na consideração das possíveis relações causais que se verificam entre a ordem do conhecimento ou da inteligibilidade e a ordem do ser. Em geral, a noção inteligida (intentio intellecta) é posterior e derivada da coisa existente, como ocorre quando tomamos conhecimento do céu pela observação e pela sensação. Mas, às vezes, ocorre o inverso, tal como ocorre quando, ao produzir uma obra, preconcebemos a forma daquilo que logo levaremos a cabo. Nesse caso, não é porque essa forma existia que nós a concebemos, mas, antes, porque nós a concebemos que a referida coisa passou a existir. Deus intelige sua essência e tudo o que sua essência implica necessariamente e conhece como há bondade em tudo aquilo que é. Por isso, as formas das coisas existentes são conseqüência da forma inteligida por Ele e, assim, são conforme a ordem com que a concebeu. Isso quer dizer que o existente não deriva ou se segue do princípio ao modo como a luz procede do luminoso ou o calor do cálido, mas precisamente do modo que concerne a um ser que possui conhecimento, que conhece a ordem de bondade das coisas e que conhece que essa ordem procede d'Ele. E, além disso, sabe que deste conhecimento flui o ser de tudo o que existe conforme a ordem que concebeu. Na medida em que ama a si mesmo, Ele, que é princípio de toda ordem e bondade, ama, ainda que acidentalmente, tal ordem de bondade, pois ela não é objeto primeiro e imediato de seu amor. Por essa razão, não é movido por esse amor nem sofre qualquer afecção, desejo ou busca. A vontade de Deus, pois, está totalmente livre de imperfeição e da perturbação de tender em direção a algo (AVICENNA 1997, 42388-4259).

Como observamos, em plena tradição neoplatônica, Avicena explica a processão de toda realidade a partir de um princípio primeiro em termos de um processo de contemplação intelectual de grau diverso. Mas diferentemente do neoplatonismo de Plotino e Proclo - e por intermédio das transformações que introduz o corpus do Plotino árabe - o princípio primeiro é concebido como uma inteligência. Assim, o ato criador do 
primeiro princípio, do qual procede o ser do criado, é explicado a partir de um ato de autoconhecimento intelectual. $\mathrm{O}$ conhecimento intelectual que Deus possui de si mesmo inclui o conhecimento de si mesmo como princípio e causa de tudo aquilo que é, bem como da ordem de bondade que emana d'Ele. A partir disso, Avicena permite-se recusar, de maneira explícita, precisamente aquelas metáforas prediletas do neoplatonismo para caracterizar a emanação: do modo que a luz e o calor emanam de suas respectivas fontes. Ao contrário, Deus age como um agente que possui conhecimento do que faz e, nessa medida, possui também uma aceitação do que deriva d'Ele. Deus aprova a bondade da criação, mesmo que ela não seja objeto primeiro de sua vontade, pois própria e imediatamente Ele só ama a si mesmo.

Até aqui, observamos, em Avicena, uma série de elementos que se reproduzirão - embora, com matizes diferentes - em Tomás de Aquino, a saber:

1. Para Avicena, Deus possui um conhecimento intelectual:

1.1 Deus conhece a si mesmo;

1.2 Conhecendo a si mesmo - enquanto é princípio - conhece também o distinto de $\mathrm{Si}$ - aos singulares somente considerados em sua universalidade;

2. Enquanto Deus tem um conhecimento intelectual do bem, na mesma medida, cabe atribuir-lhe vontade:

2.1 Deus quer ou ama a si mesmo;

2.2 Ao querer a si mesmo, quer - acidentalmente - o distinto d'Ele.

Em uma obra recente, Rahim Acar explorou os alcances desse paralelismo entre Tomás de Aquino e Avicena e explicou as diferenças de matiz em razão das diferentes estratégias de ambos os autores em relação à configuração da linguagem teológica ${ }^{3}$. Em particular, Acar explica que (contra a interpretação tradicional dos medievais e de intérpretes do século XX) em que pese, para Avicena, a criação aconteça necessariamente, isso não significa que Deus não aja como um agente voluntário. Como bem assinala o intérprete, o que Avicena negará é que, ao criar, Deus tenha uma intenção, isto é, um tipo de inclinação ou tendência em direção a um objeto externo ou que a criação possa constituir um fim para Deus como se o resultado de sua ação pudesse obter um benefício 
(ACAR 2005, 132-149). A tese '1' é impossível porque torna Deus um ser dependente de algo externo. Já '2' é impossível porque, sendo Deus o bem supremo, não há nenhum outro bem relativo inferior que possa contribuir para aumentar sua perfeição e bondade.

Para Avicena, se, em Deus, houvesse uma intenção de produzir as coisas, isso equivaleria a introduzir uma multiplicidade n'Ele pois haveria n'Ele algo que seria a causa da sua intenção, a saber, o conhecimento e a ciência que o indicariam a necessidade de tender até isso. A bondade que ai haveria ou um benefício ou utilidade que tal intenção lhe proporcionaria, tudo isso é impossível. Portanto, todo ser que procede d'Ele não o faz de um modo natural (secundum viam naturae), como se procedesse de uma maneira que seu conhecimento e sua aprovação (beneplacitum) não interviessem - não poderia ser assim, uma vez que se trata de um ser que é inteligência pura que intelige a si mesmo. E, por isso, é preciso que Ele entenda que d'Ele mesmo se segue necessariamente a emanação de tudo - na medida em que conhece a si mesmo como inteligência pura e como princípio e que conhece tudo o que deriva dele, enquanto é seu princípio. E, como em sua essência não há nada que impeça que todas as coisas emanem d'Ele, sabe que sua perfeição e excelência é tal que d'Ele flui toda bondade e que isso é um acidente necessário da sua glória, a qual é amada por si mesma (AVICENNA 1997, 47640_4782).

Portanto, que a criação seja um efeito necessário de Deus, enquanto sua causa, não implica que não seja produto da sua vontade, embora não o seja nos moldes em que uma intenção o é, tal como é próprio da modalidade da vontade humana. Segundo Acar, há dois conceitos chave para articular a liberdade de Deus e a necessidade da criação: os de generosidade e concomitância (ACAR 2005, 145). De acordo com o primeiro, Deus é o ser maximamente generoso porque em seu fazer não obtém nada em troca de sua ação. De acordo com o segundo, a criação é um concomitante necessário da essência divina, o que significa que não está incluída na essência divina. Em outras palavras, Deus não precisa criar para ser quem é, mesmo que a criação siga-se necessariamente da essência divina. Ora, um acidente é um atributo que não está incluído na essência de uma coisa e, nesse sentido, opõe-se a um constitutivo da essência, mas que se desprende da essência da coisa. Por exemplo, a ajuda mútua não é um constitutivo do conceito de amizade, pois sua definição 
é, antes, "querer o bem do outro". No entanto, da amizade se segue necessariamente que os amigos procurem ajuda recíproca. Generosidade e concomitância permitem assegurar, ao mesmo tempo, a independência de Deus com respeito ao universo, a existência necessária do universo a partir d'Ele.

\section{III}

A noção de Deus, como ser necessário por si, aparece desde os primeiros passos da construção argumentativa da teologia de Tomás de Aquino. Como fica claro na terceira via para a prova da existência de Deus. A prova parte das noções de possível e necessário e chega à existência de um ser necessário por si, o qual não possui a causa de sua necessidade em outro, mas que é causa da necessidade dos outros seres - dos possíveis e dos necessários que possuem causa de sua necessidade (ST I q. 2, a. 3). Curiosamente, esse argumento não aparece na Suma contra gentiles no capítulo dedicado às demonstrações da existência de Deus, mas, apenas mais adiante, incluído num par de argumentações que demonstram que Deus é eterno e que é causa do ser de todas as coisas. Em tais argumentos, encontramos incorporados e remodelados alguns dos elementos dos três teoremas modais da metafísica aviceniana.

Segundo o primeiro argumento, vemos no mundo algumas coisas que podem tanto ser como não ser, as geráveis e corruptíveis. Sendo assim, o que pode ser tem uma causa, pois, como em si se acham igualmente disposto os dois extremos do ser e do não ser, é preciso, para apropriar-se do ser, que isso ocorra por alguma causa. Mas, como nas causas não se pode regressar ao infinito (e aqui Tomás remete às provas aristotélicas do movimento já expostas no capítulo 13) é preciso que haja um ser necessário. Tal como ocorrerá na Suma teológica, o argumento não se conclui aqui, pois considera a possibilidade de duas classes de ser necessário: o que tem causa de sua necessidade em outro e o que não a tem, mas que é necessário por si mesmo. Como tampouco se pode ir ao infinito na série dos seres necessários que têm a causa da sua necessidade em outro, é preciso afirmar que há um primeiro necessário que é necessário por si. Tomás acrescenta que esse ser é Deus, uma vez que é 


\section{2}

causa primeira, e aplica essa conclusão, como dissemos, não à confirmação da existência de Deus, mas à demonstração da sua eternidade. Com efeito, esse ser necessário, como todo ser necessário - que não pode não existir - é eterno (SCG I 15, \ 5).

O segundo argumento pertence ao segundo livro e corresponde ao início do tratamento do tema da criação. Tudo o que pode ser ou não ser tem alguma causa, pois, considerado em si mesmo, acha-se disposto em direção a qualquer dos extremos e, assim, é preciso que haja algo distinto que o determine até um deles. Por isso, como não é possível regressar ao infinito, é preciso que haja algo necessário que seja causa de todos os seres que podem ser e não ser. Mas há um certo ser necessário que tem causa de sua necessidade, em relação à qual tampouco se pode ir ao infinito. É preciso, assim, ascender a algo que seja necessário por si. Esse algo não pode ser senão um - e aqui Tomás de Aquino refere-se ao que fora demonstrado no primeiro livro. Portanto, tudo aquilo que não é esse ser necessário deve ser referido a Ele como a sua causa de ser (SCG II 15, \6).

Como vemos, esses argumentos recorrem a elementos característicos da metafísica modal de Avicena: a indeterminação intrínseca do possível igualmente aberto ao ser e ao não ser e a consequente necessidade de uma causa que o determine em relação a algum desses contrários. Mesmo o segundo argumento baseia-se na demonstração igualmente aviceniana de que o ser necessário não pode ser senão um. Essa noção de ser necessário por si (necesse-esse per se) desempenha um papel importante na demonstração de vários pontos do tratamento da essência divina na Suma contra gentiles, nos argumentos que demonstram que, em Deus, essência e ser se identificam (SCG I 22, $\left.\int \mathcal{S} 2,4,5\right)$, que Deus não pode ser designado através de uma diferença substancial (SCG I 24, \ 2) e que não é o ser formal de todas as coisas (SCG I 26, \4). Em geral, demonstrou-se que particularmente o capítulo quarto do tratado VII da Metafísica de Avicena tem uma forte presença dentro da Suma contra gentiles: Tomás segue de perto o texto aviceniano, quase ao nível da paráfrase, embora também opere importantes modificações e correções (JUDY, 1975-76).

A sequencia temática de Tomás de Aquino na Suma contra gentiles corresponde, em linhas gerais, com a que vimos em Avicena. Depois da via da remoção, que corresponde à simplicidade divina (SCG I 14-27), 
Tomás considera a perfeição de Deus e, como seu corolário, a semelhança das criaturas (SCG I 28-29). Isso habilita o tratamento dos nomes divinos que culmina na teoria da analogia (SCG I 30-36). Uma vez que o discurso sobre Deus é tornado possível por meio de termos positivos, considera-se a bondade divina (SCG I 37-41), sua unidade e infinitude (SCG I 42-43) e, por último, sua inteligência. O itinerário de Tomás de Aquino pode ser visto como o desenvolvimento e ampliação da sequência aviceniana: necessidade - simplicidade - perfeição - bondade - inteligência.

Tomás demonstra que Deus é um ser inteligente através de vários argumentos, um dos quais é precisamente uma paráfrase do argumento aviceniano baseado na equação entre a inteligibilidade - ou intelecção e a imaterialidade. As formas são inteligidas em ato enquanto são abstraídas da matéria e constituem uma unidade com o intelecto no ato de inteligir. Portanto, para que algo seja inteligente é preciso que esteja isento de materialidade. Isso ocorre maximamente em Deus, que é absolutamente imaterial (SCG I 44, \5). Outros argumentos baseiam-se nas conclusões das vias para a existência de Deus: um par deles deduz a inteligência de Deus a partir da condição daquele primeiro motor que é conclusão da via do movimento (SCG I 44, \$ 2-3), e um terceiro a partir da condição daquele primeiro ordenador que estabelece os fins das coisas (SCG I 44, \7). Outro argumento baseia-se no fato que a Deus, ao ser sumamente perfeito, não pode faltar a perfeição da inteligência, a qual é encontrada em algumas criaturas (SCG I 44, \6).

Na continuação, Tomás de Aquino demonstrará que tanto o inteligir mesmo de Deus quanto seu objeto identificam-se com sua essência, tal como Avicena demonstrou que, em Deus, coincidem a inteligência, o inteligido e a intelecção. Entre outras razões, seguindo a linha traçada por Aristóteles em Metafísica XII, 9, Tomás argumenta que nem a ação divina de inteligir nem o objeto de sua intelecção podem constituir algo distinto de seu ser, pois, nesse caso, Deus estaria em potência em relação à atualização correspondente - ou da capacidade de inteligir (SCG I 45, \ 5) ou da recepção da espécie inteligível (SCG I 46, \3) - ou bem o inteligir constituiria, em Deus, uma propriedade ou acidente que se Lhe acrescenta (SCG I 45, \3), o mesmo que sua ciência ou conhecimento (SCG I 46, \$ 4), o que é impossível, dada a absoluta simplicidade da essência divina. 


\section{4}

A partir dessa base, deparar-nos-emos com um esquema análogo ao que fora encontrado em Avicena, com as seguintes exceções:

1. Também, para Tomás de Aquino, Deus tem um conhecimento intelectual:

1.1 Deus conhece própria e primeiramente a sua própria essência;

1.2 Conhecendo sua própria essência, conhece nela todas as outras coisas - com um conhecimento próprio e adequado, ou seja, em sua variada especificidade e sua singularidade -;

2. Pelo mesmo fato que Deus é um ser inteligente, deduz-se que Deus é um agente voluntário:

2.1 O objeto principal da vontade divina é sua própria essência;

2.2 Ao querer a si mesmo, Deus quer também as demais coisas, somente enquanto ordenam-se a Ele como a seu fim.

Entre os argumentos com os quais Tomás de Aquino demonstra que Deus conhece o que é distinto de si, há um par que se move num âmbito similar ao aviceniano. Conhece-se suficientemente o efeito pelo conhecimento de sua causa. Mas Deus é, por sua essência, causa do ser das coisas. Portanto, se Deus conhece plenamente sua essência, conhecerá também as demais coisas. Nesse mesmo sentido, quem conhece completamente uma coisa conhece tudo o que se pode dizer verdadeiramente dela e o que lhe convém segundo sua natureza. Mas a Deus convém, segundo a sua natureza, o ser causa de outras coisas. Portanto, conhece a si mesmo como causa, o que implica que possua um conhecimento do causado (SCG I 49, \& 3). Até aqui, estamos, de algum modo, no mesmo ponto de Avicena: Deus deve conhecer as coisas porque, conhecendo a si mesmo, conhece-se como princípio e causa de todas as coisas. Mas Tomás acrescenta aqui um princípio importante: o axioma da preexistência do efeito na causa, "todo agente faz o semelhante a si" (omne agens agit sibi simile). Se Deus é um ser inteligente, deve haver n'Ele uma preexistência do efeito. Mas, enquanto é um ser inteligente, essa preexistência deve dar-se de um modo inteligível, o que é o mesmo que dizer que deve conhecer seu efeito intelectualmente (SCG I 49, \$ 3 e ST I q. 14, a. 5).

Em oposição a Averróis, Tomás dirá que Deus possui um conhecimento das coisas não só em geral, sob a noção comum de ente enquanto 
ente, mas também um conhecimento próprio das coisas (SCG I 50); e, mais adiante, acrescentará que Ele possui conhecimento também dos singulares (SCG I 43-45). Mas, se Deus possui um conhecimento intelectual das múltiplas coisas distintas de Si, ter-se-á que investigar como se dá a relação entre essa multiplicidade e Deus. Tal multiplicidade de coisas inteligidas não pode possuir um ser distinto em Deus mesmo nem pode ser constituída de essências separadas ou formas existentes por si - ao modo dos platônicos - e, muito menos, estar em outro intelecto que não no divino (SCG I 51-52). Portanto, essa multiplicidade não pode estar senão no próprio entendimento divino. Nesse caso, como explicar isso sem comprometer a simplicidade divina?

No âmbito da explicação geral do conhecimento que Tomás oferece, o cognoscente conhece através de uma species; a qual constitui o princípio formal da operação intelectual. A partir dela, o intelecto forma uma conceptio. Tanto uma quanto outra são uma semelhança da coisa conhecida. Em Deus, a conceptio que Ele concebe, seu Verbum, não só é semelhança de si mesmo, mas também semelhança de todas as coisas: "assim, pois, através de uma espécie inteligível, que é a essência divina, e de uma noção intelectual, que é o verbo divino, múltiplas coisas podem ser inteligidas por Deus" (SCG I 54, \ 5).

Para Tomás, que Deus possua vontade é algo que se deriva imediatamente do fato que é um ser inteligente. É preciso ter presente que, em Tomás, todo o real conta com um appetitus, uma inclinação ou orientação graças a qual tende ou se move até a aquisição de seu próprio bem, no qual repousa e encontra sua satisfação, quando o alcança. Os seres que contam com conhecimento movem-se por esse appetitus em virtude de uma representação que possuem do bem; os animais, em virtude de uma representação sensível e, o homem, em virtude da ratio boni que é captada pelo intelecto. O tipo de appetitus que tende em direção ao bem captado intelectualmente é o que se chama vontade. Certamente, em Deus, não haverá appetitus no sentido de um desejo ou aspiração em direção a algo do qual precisa, mas apenas diretamente a complacência ou deleite no sumo bem inteligível, que não é outro que Ele mesmo (SCG I 72, \$\$ 2, 4, 5, 9 e ST I, q. 19, a. 1, especialmente ad 2).

Assim sendo, tal como o objeto primeiro e imediato da intelecção de Deus é sua essência mesma, do mesmo modo, o objeto primeiro e imedia- 


\section{6}

to de sua vontade será também sua própria essência. Não poderia ser de outro modo, uma vez que, como dissemos, há vontade porque há conhecimento intelectual e o bem inteligido, que é objeto de sua vontade, é precisamente sua própria essência. De outro lado, se o que é desejado imediatamente por Deus fosse um fim distinto ou externo, Deus seria movido por ele - sendo que é absolutamente imóvel (SCG I 74, \$3) - ou simplesmente sua vontade teria uma causa - sendo que Ele é não causado (SCG I 74, \ 4). E tal como, ao inteligir sua própria essência, Deus intelige as coisas distintas de $\mathrm{Si}$, do mesmo modo, ao querer a Si mesmo, Deus quer as outras coisas. Aqui o conceito chave vem a ser a relação de ordenação ao fim que todas as coisas possuem em relação a Deus.

Com efeito, aquele a quem corresponde querer primeiramente o fim, corresponde também querer aquelas coisas que se ordenam ao fim (ea quae sunt ad finem) e querê-las em razão do fim (ratione finem). Como Deus é o fim último de todas as coisas, na medida em que quer a Si mesmo, quer também as coisas que se ordenam a Ele (SCG I 75, \2). A isso, Tomás de Aquino acrescenta argumentos baseados na noção de difusividade do bem. Deseja-se a perfeição de tudo aquilo que é querido e amado. Quando amamos algo, queremos que isso seja ótimo e queremos, na medida do possível, multiplicá-lo e fazê-lo melhor. Mas a essência divina não é por si aumentável nem multiplicável, pois é apenas segundo alguma similitude que é participada por muitos. Deus quer, portanto, uma multiplicidade de coisas pelo fato que quer sua essência e sua perfeição (SCG I 75, \4). Segundo o princípio de extração procliana, que Tomás cita recorrentemente, quanto mais perfeita é uma virtude ou capacidade causal, a mais coisas se estende a órbita da sua causalidade. Sendo assim, a causalidade do fim consiste na razão pela qual todas as outras coisas são desejadas. Uma vez que a ciência divina é perfeitíssima, em relação à bondade e ao fim, ela difunde sua causalidade maximamente à maior quantidade de coisas, de modo que, em razão de sua bondade, muitas coisas são queridas (SCG I 75, \6).

Chegamos, assim, ao ponto principal, o cerne da questão da necessidade ou contingência da relação causal entre a causa primeira e seu efeito. Como vimos, segundo Avicena, Deus ama a si mesmo e, ao desejar a sua própria essência, deseja a ordem de bondade que flui dela. Por isso, é desejada "acidentalmente", isto é, não como objeto primeiro de seu 
desejo, como se Deus tivesse a intenção de criar. Tomás dirá ainda mais claramente: Deus quer necessariamente sua própria essência, mas quer contingentemente as outras coisas que se ordenam a ela.

$\mathrm{O}$ fato de um agente possuir uma vontade necessária poderia parecer, a primeira vista, contraditório. Mas não o é quando se leva em conta o âmbito geral da ética aristotélica, da qual Tomás de Aquino parte. A vontade relaciona-se necessariamente com o fim último, mas não da mesma maneira que os meios elegíveis com vistas ao fim. Todos os homens desejam, por natureza, a felicidade, o que não quer dizer que estejam de acordo sobre em que consiste a felicidade. Em termos mais gerais, todo agente age com vistas a um fim e esse é sempre um bem, seja verdadeiro ou aparente. A partir dessas premissas, podemos dizer que, assim como o homem deseja necessariamente a felicidade, Deus deseja necessariamente a si mesmo, pois deseja-se por si mesmo e não como meio para outra coisa. O fim ocupa, pois, no âmbito das faculdades produtivas e da ação, o papel que desempenham os princípios indemonstráveis no âmbito do conhecimento especulativo: assim como o intelecto tende aos primeiros princípios, a vontade também inclinase necessariamente ao fim último, de modo que não pode não o querer (SCG I 80, \$S 2-3).

No entanto, precisamente sobre as mesmas bases, concluir-se-á que a vontade divina não mantém uma relação necessária, mas contingente com as coisas externas, uma vez que não são objeto principal da vontade divina, mas, sim, desejadas enquanto estão ordenadas em relação a Deus. Com efeito, em termos gerais, uma vontade não tem razão para escolher necessariamente certos meios, se o fim pode ser alcançado sem eles: assim como o médico não está obrigado a dar ao doente um medicamento sem o qual ele também poderá se curar. A vontade divina pode existir sem outras coisas e tais coisas não lhe acrescentam nada. Por isso, não possui necessidade de as querer em virtude de querer a bondade delas (SCG I $81, \sqrt{\int}$ ). Aqui encontramos algo similar à idéia aviceniana que Deus não obtém nenhum benefício ou proveito de sua ação em direção a outras. De onde se compreende por que Tomás de Aquino cita tão frequentemente a frase se Avicena que só Deus é "maxime liberalis" (In Sent. I d. 18, q. 1, a. 3; I d. 45, q. 1 a. 2; II d. 3, q. 4, a. 1, arg. 3; II d. 11, q. 2, a. 1 arg. 2; SCG I 93, \ 7; De pot.q. 7, a. 10; De ver.q. 23 a. 4). 
Outro argumento mostra a independência da vontade divina em relação a qualquer fim ou bem que não seja o próprio Deus. Como o bem inteligido é o objeto próprio da vontade, pode haver vontade de qualquer coisa concebida pelo intelecto, salvando-se a ratio boni. A convertibilidade entre ser e bem pareceria exigir que o não-ser não poderia ser objeto da vontade. No entanto, às vezes o não-ser pode cair sob a vontade sob a rubrica de um bem acrescentado que é salvo, mesmo que não necessariamente: pode ser que seja bom o ser de alguma coisa, não existindo outra. Portanto, a vontade não pode não querer somente aquilo que, por seu conceito, suprima totalmente a ratio boni. É evidente que um bem com tais características é unicamente Deus. Portanto, a vontade pode querer que nada exista a não ser Deus. E, como em Deus, há uma vontade plena, segundo toda a sua potência - porque n'Ele tudo é perfeito - Deus pode querer o não-ser de qualquer coisa que não seja Ele mesmo (SCG I 81, \$3).

Além do fato de as coisas externas, que Deus quer, não poderem representar um objeto necessário para Seu querer, é preciso notar que a eternidade, necessidade e imutabilidade que caracterizam a essência divina, fazem também com que, inclusive o querer delas mesmas não possa ser um querer necessário. Para explicar isso, Tomás de Aquino recorre a uma distinção, que remonta a Aristóteles, entre a necessidade absoluta - a necessidade que pertence a uma coisa enquanto tal - e a necessidade hipotética - a qual pertence a algo somente sob uma certa condição, sob a suposição ou como consequência de uma determinada coisa ou fato. Como a vontade divina em si mesma não pode estar sujeita à variação, por mais que algo mantenha uma relação contingente com a vontade de Deus, isso não significa que, a partir do momento que Deus o quer, ou enquanto Deus o quer, não o queira necessariamente. Com efeito, a vontade de Deus é imutável. Mas, em tudo aquilo que é imutável, uma vez que algo existe, não é possível que esse algo não se dê, dado que o movimento consiste precisamente na existência de algo agora de outro modo do que era antes. Portanto, uma vez que Deus queira algo, necessariamente ele o quer ex suppositione (SCG I 83, \$2). Por outro lado, tudo o que é eterno é necessário. O fato de Deus querer que exista algo causado implica que esse algo seja eterno - pois, tal como seu ser, seu querer é mensurado pela eternidade. Portanto, seu querer é 
necessário, mas não com necessidade absoluta, e sim hipotética (SCG I

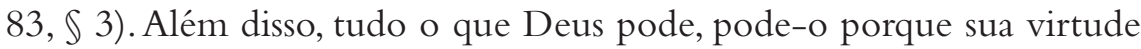
não diminui. Mas, então, não pode não querer agora aquilo que se afirmou que quis, pois sua vontade não pode mudar. Portanto, não pode não querer o que quis. Consequentemente, é necessário ex suppositione que tenha querido o que quis e o que quer (SCG I $83, \$ 4$ ).

\section{IV}

Há um conjunto de noções centrais da metafisica aviceniana que ocupam um lugar decisivo na constituição da metafísica de Tomás de Aquino. As distinções entre essência e ser, nos seres criados, entre agente natural, que age segundo movimento ou mutação, e o agente divino, que é o doador do ser, são chaves para elaborar a diferente condição ontológica de Deus e da criatura e para conceitualizar a relação causal mesma que se observa entre ambas sob o nome de criação. Para além das reformulações ou das eventuais críticas que Tomás possa fazer sobre essas noções, o filósofo árabe proporciona ao doutor cristão um repertório de ferramentas conceituais que permitem ultrapassar o marco inicial da ontologia aristotélica da substância e da causalidade imanente da fisica e elevar-se, assim, ao plano de uma metafísica creacionista. No entanto, fica claro que Tomás de Aquino possui, em relação a Avicena, uma discrepância sobre três pontos fundamentais acerca da criação. $O$ alvo principal de suas críticas é: o necessitarismo que, a seu ver, Avicena sustenta - Deus atua como um agente natural determinado ad unum; a criação mediata - segundo o princípio que "do uno não pode surgir senão o uno" (ab uno non fit nisi unum) - e a eternidade do mundo - se a ação de Deus é eterna, o mundo necessariamente deve ser eterno. As considerações de Avicena sobre a inteligência e a vontade de Deus permitem relativizar a distância em relação a Tomás de Aquino acerca do primeiro ponto. Além dessa precisão, restam ainda dois outros indubitáveis e insuperáveis pontos de discrepância entre Avicena e Tomás de Aquino.

O exame do paralelismo entre nossos dois autores mostra estratégias similares ou análogas quanto à forma de combinar a suficiência de Deus e, ao mesmo tempo, sua liberdade para agir. Um e outro procuram salvar, 
de modo similar ou a seu modo, tanto a suficiência do primeiro princípio quanto a conexão com o universo dependente d'Ele. A solução estende-se ao plano de uma nova formulação das relações entre o ser e o inteligível. O primeiro princípio é identificado com o Ser mesmo, o qual é radicalmente distinto de todos os outros seres cujo ser é causado por Ele. Mas, ao mesmo tempo, é interpretado como uma inteligência que concebe a si mesma e que, ao conceber a si mesma, concebe tudo o mais. E, na medida em que se relaciona com tudo o mais, enquanto agente intelectual, relaciona-se com isso como um agente voluntário. Tanto no âmbito do conhecimento quanto no da vontade, Deus relaciona-se suficientemente com sua própria essência e, ao mesmo tempo, com tudo aquilo que não é Ele, sem que essa relação comprometa a sua suficiência e, com certeza, sua simplicidade, imutabilidade, necessidade e eternidade. Através do conhecimento que Deus possui de si mesmo, Ele pode conhecer todas as coisas distintas de si e, a partir do fato de querer a si mesmo, pode vir a querer todas as coisas distintas de si. Assim, institui-se uma relação entre as coisas exteriores a Deus e a essência divina que pode estar embasada, de algum modo, na essência divina, mas não mantém uma relação necessária com a essência divina.

Tendo por base esse paralelismo inicial, Acar considera a concordância entre Tomás e Avicena sobre os seguintes dois pontos fundamentais: 1) Deus não está obrigado a criar - não há nada externo a Ele que possa forçá-lo; 2) Deus não precisa criar para ser o que é - Deus não obtém nenhum benefício nem nada se acrescenta ao ser pela criação. A partir dessas duas premissas, pareceria poder inferir-se que a existência do mundo não é necessária. Se Deus não está obrigado a criar e se sua perfeição é independente da eventual existência do universo, esta última é, em si mesma, contingente. Conforme a interpretação de Acar, Tomás de Aquino concede que a existência do mundo não é necessária segundo uma necessidade absoluta, mas segundo necessidade hipotética, isto é, na medida em que se relaciona com a vontade de Deus. No entanto, Avicena, depois de afirmar que Deus não atua como um agente natural determinado a agir, assinala que a criação é um acidente necessário de Deus. Levando em conta a coincidência entre ambos os pensadores acerca das premissas iniciais, Acar investiga se a conclusão que se segue de ambas as premissas deve ser também similar: a necessidade do mundo, afirmada 
sem qualificação por Avicena, corresponderia ao que Tomás de Aquino chama de necessidade hipotética (ACAR 2005, 165).

No entanto, nessa reconstrução, que iguala ambas as concepções da necessidade do mundo, fica encoberto um matiz de diferença pequeno, mas decisivo. Apesar dos paralelismos expostos, Avicena e Tomás de Aquino não compartilham a mesma visão sobre a necessidade ou contingência do mundo. Em Avicena, a ambivalência é radicalmente primária ou constitutiva: intrinsecamente o mundo é possível, mas é necessário por outro. A necessidade em questão é a necessidade da implicação, segundo a qual o efeito está em relação com sua causa. Porém, essa necessidade de implicação, com a qual Avicena vincula a necessidade do mundo com sua causa necessária, não corresponde exatamente à aplicação que Tomás de Aquino faz da necessidade hipotética: que Deus queira o mundo com necessidade hipotética é algo que se refere antes à necessidade do querer de Deus, sem que isso implique alguma conclusão especial em relação à contingência ou necessidade do mundo. De fato, Tomás demonstra expressamente, depois de ter demonstrado que Deus quer o outro de si com necessidade hipotética, que a vontade divina não suprime a contingência nas coisas, nem às confere necessidade.

Deixamos precisamente para esse momento final a exposição dos argumentos de Tomás de Aquino a respeito desse ponto. Deus quer em maior grau o bem da totalidade de seus efeitos do que de algum bem particular, uma vez que é naquele que se dá uma semelhança mais completa de sua bondade. Mas, para a completude do universo, é preciso que haja alguns seres contingentes, caso contrário, nem todos os graus dos entes estariam contidos no universo. Deus quer, portanto, que haja alguns seres contingentes (SCG I 85, \3). Por outro lado, o bem do universo consiste numa certa ordem, como é assinalado até o final do livro XII da Metafísica aristotélica. Mas a ordem do universo requer que haja algumas causas variáveis porque, dentre os seres que contribuem com a perfeição do universo, estão os corpos, os quais não movem senão sendo movidos. Tendo isso em vista, de causas variáveis seguem-se efeitos contingentes, uma vez que o efeito não pode ser mais firme do que sua causa. Tomás explica que, por mais que a causa remota seja necessária, se a causa própria é contingente, seu efeito será contingente, como ocorre no caso dos corpos inferiores que são contingentes em virtude das causas próprias de seu mesmo nível, 
mesmo que suas causas remotas, os corpos celestes, sejam necessárias. Deus quer, portanto, que algumas coisas aconteçam contingentemente (SCG I 85, 4). Em geral, a necessidade hipotética na causa não implica uma necessidade absoluta no efeito. Do fato que Deus queira algo na criatura com necessidade hipotética, não se segue, por isso, que haja na criatura necessidade absoluta, que é o único tipo de necessidade que exclui totalmente a contingência. Consequentemente, a vontade divina não exclui a contingência das coisas queridas (SCG I 85, \5).

Isso parece indicar que, em última instância, o modo de conceber a necessidade ou a contingência da relação da causa primeira com seu efeito não determina a maneira de conceber a necessidade ou a contingência no interior do universo. Em que pese o paralelismo ou a coincidência parcial que se pode encontrar entre Avicena e Tomás de Aquino, ambos os autores têm uma interpretação diferente da combinação de necessidade e contingência no universo, a qual corresponde a diferentes preferências ou modalidades filosóficas. Em Avicena, encontrase uma rígida versão do universo, segundo a qual tudo o que existe, enquanto tal, é necessário: tudo o que existe, a partir do momento em que veio a ser, saiu da indeterminação da possibilidade. Em um mundo com tais características não há, realmente, lugar nenhum para a contingência, a não ser o da apreciação relativa e limitada dos fenômenos que ainda não tenham sido compreendidos na sequência necessária e completa que os liga à causa primeira. Isso é ratificado pela doutrina aviceniana do acaso, a qual pode ser compreendida em consonância com o determinismo causal exposto em sua Metafísica (BELO 2004).

Tomás de Aquino compartilha com Avicena a tese segundo a qual todas as causas contingentes e inferiores podem ser reduzidas a uma única causa per se, universal. No entanto, isso não modifica uma concepção do universo que exige uma mistura conveniente de graus de contingência e necessidade. Embora passe desapercebido a muitos comentadores de Tomás, no universo do Aquinate, Deus não é o único ser necessário, pois há outros seres necessários, seres que não podem não existir devido a sua imaterialidade - as inteligências separadas - ou a sua incorruptibilidade os astros. Em todo caso, Deus é o único ser absolutamente necessário ou necessário por si. Mas é igualmente importante que no universo haja seres contingentes. A explicação da exigência dessa contingência reside na 
necessidade de resguardar a liberdade humana. A respeito disso, é preciso observar que a concepção tomista da influência de Deus na ação humana não tornará o assunto mais simples. Além de explicações antropológicas, Tomás oferece razões cosmológicas para defender uma versão de um mundo parcialmente contingente. É melhor ou preferivel um universo no qual haja mistura de necessidade e contingência, a fim de representar melhor as múltiplas perfeições de Deus e uma ordem universal que inclua causas variáveis, para que haja uma diversidade de graus nas coisas. Embora tais características possam ser justificadas como elegíveis pela vontade divina, é preciso lembrar que, para Tomás, como vimos, o objeto da vontade é tal porque se apresenta com uma ratio boni captável pelo intelecto. Por isso, um universo que inclua algum grau de contingência é racional e objetivamente bom.

Talvez haja, no fundo dessa discrepância entre Avicena e Tomás de Aquino, uma diferente valoração do ideal da suficiência explicativa filosófica. Pode ser que Avicena represente o ideal segundo o qual a melhor explicação que, por ser acabada e total, torne seu objeto necessário e, nesse sentido, não deixe margem alguma à contingência. Talvez Tomás de Aquino represente outro ideal segundo o qual, embora a explicação sempre estabeleça um vínculo necessário, é melhor, no entanto, se ela conserva uma contingência residual em seu objeto. Além disso, uma boa explicação é também aquela que reconhece que nem tudo tem explicação ou, melhor ainda, a que explica tudo porque explica em que consiste o fato de algumas coisas não terem explicação.

1 A relação entre os termos "princípio" " "causa" merece algumas especificações: cf. Arist. Met. V 1-2, 1012 b24 ss.. No final deste trabalho, trataremos tais termos como intercambiáveis, sobretudo na medida em que nos referirmos à causa primeira.

2 Avicena deixa esse ponto em suspenso porque mais adiante dirá que é possível uma regressão ao infinito no caso das causas acidentalmente ordenadas.

3 Cf. Acar (2005) esp. Caps 2 e 3. Seguindo a distinção de David Burrell entre as características formais (formal features) de Deus - as que informam melhor o modo de ser de Deus: necessidade, imutabilidade, eternidade, etc. - e as características ou propriedades de perfeição - as que dizem efetivamente algo do que Deus é, como a bondade, a sabedoria, etc. -, Acar interpreta que Avicena tende a conceber as propriedades de perfeição de Deus como intrinseca- 


\section{4}

mente modificadas pelas características formais, enquanto que Tomás de Aquino consideraria as propriedades de perfeição em si mesmas, precisamente em virtude de possuir um dispositivo linguístico apropriado, como é o caso da analogia (ACAR 2005, 119-127).

\section{Referências bibliográficas}

ACAR, R. 2005; Talking about God and Talking about Creation: Avicenna's and Thomas Aquinas' Positions. Brill, Leiden - Boston.

AVICENNA LATINUS. 1977. Liber de Philosophia Prima sive Scientia Divina, édition critique de la traduction médiévale par S. van Riet, introduction doctrinale par G.Verbeke. Leiden, Brill.

AVICENNA. 1926. Metaphysices Compendium, ed. Carame, Roma.

BELO, C. 2004. "Ibn Sina on Chance in the Physics of As-Shifa". MCGINNIS, J. e REISMAN, D.C., Interpreting Avicenna: science and philosophy in medieval Islam, Leiden, Brill.

JUDY, A. 1975 e 1976. “Avicenna's Metaphysics in the Summa contra gentiles” en Angelicum 52 (1975) pp. 340-384; pp. 541-586; 53 (1976) pp. 184-226.

MARMURA, M.E. 1962. "Some aspects of Avicenna's theory of God's knowledge of particulars" Journal of the American Oriental Society 82, pp. 299-312. 